\title{
Notes on the vocalizations of Oceanic Flycatcher (Myiagra oceanica)
}

Peter Boesman

In the following we briefly analyze and compare voice of the three (non-extinct) races of Oceanic Flycatcher (Myiagra oceanica). We also try to quantify the extent of any vocal differences using the criteria proposed by Tobias et al. (2010), as a support for taxonomic review. We have made use of sound recordings available on-line from Xeno Canto (XC) and Macaulay Library (ML).

All races have several 'song-like vocalisations'. An overview of all vocalisations based on available recordings:

erythrops (Palau)

song:

* a repeated series of 3-4 whistles at about even pitch

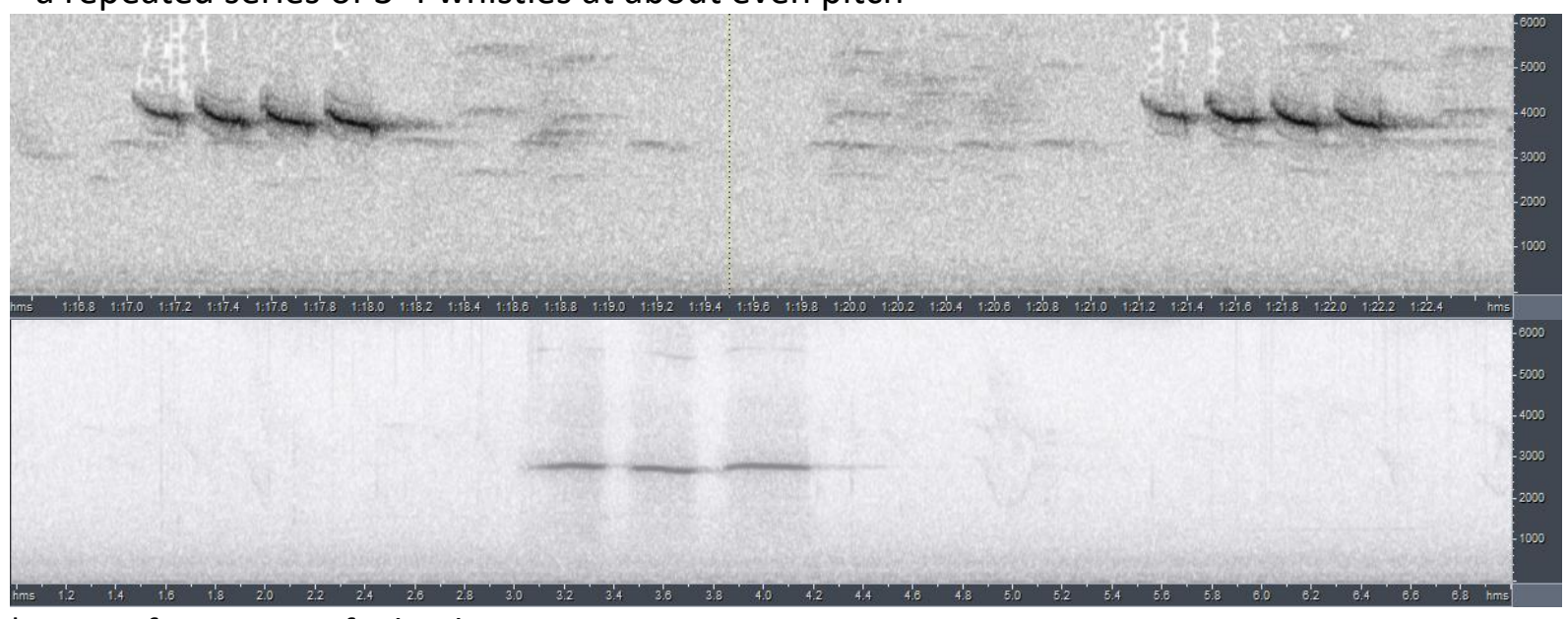

* a very fast series of whistles

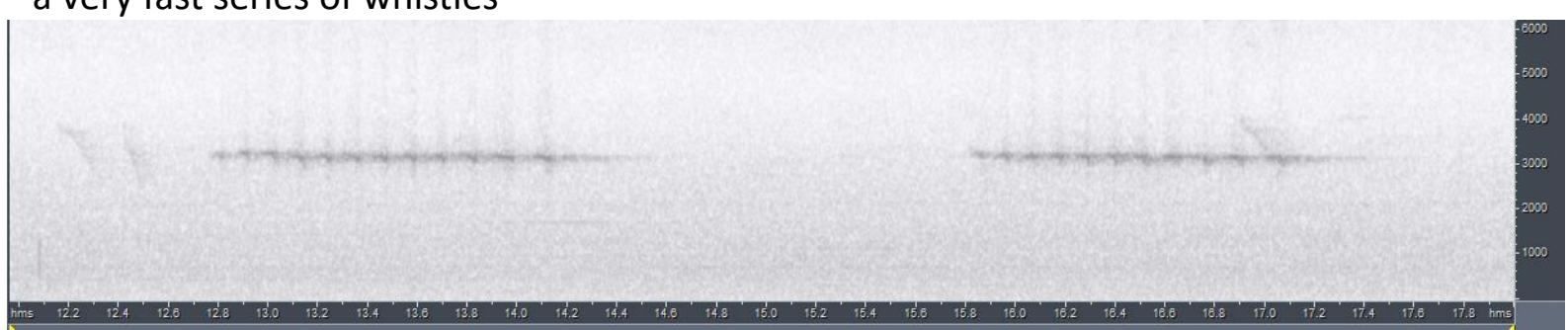

* a harsh grating note ending with a pure short syllable

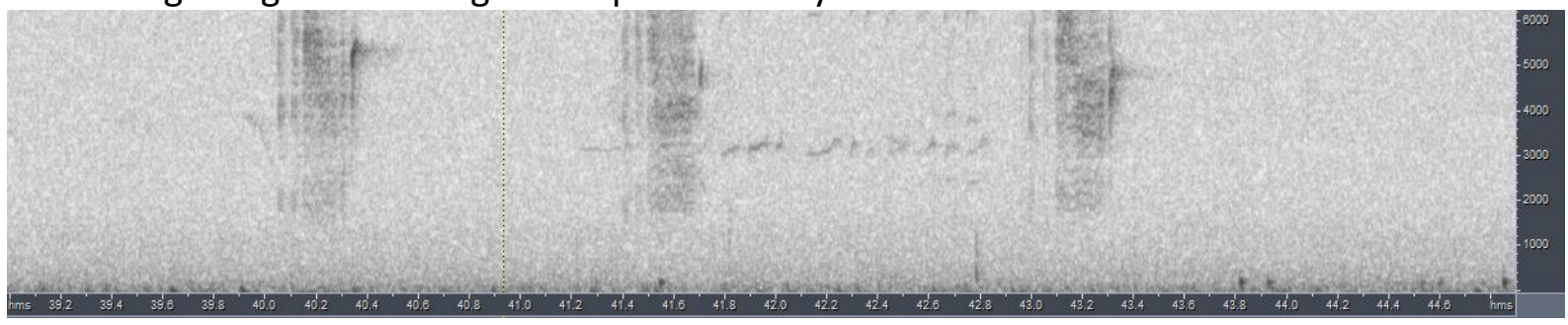




\section{HANDBOOK OF THE \\ BIRDSPF THE WORLD Alve}

\section{ORNITHOLOGICAL NOTES}

oceanica (Chuuk)

* a combinations of short chik notes, harsher grating notes and downslurred whistles:

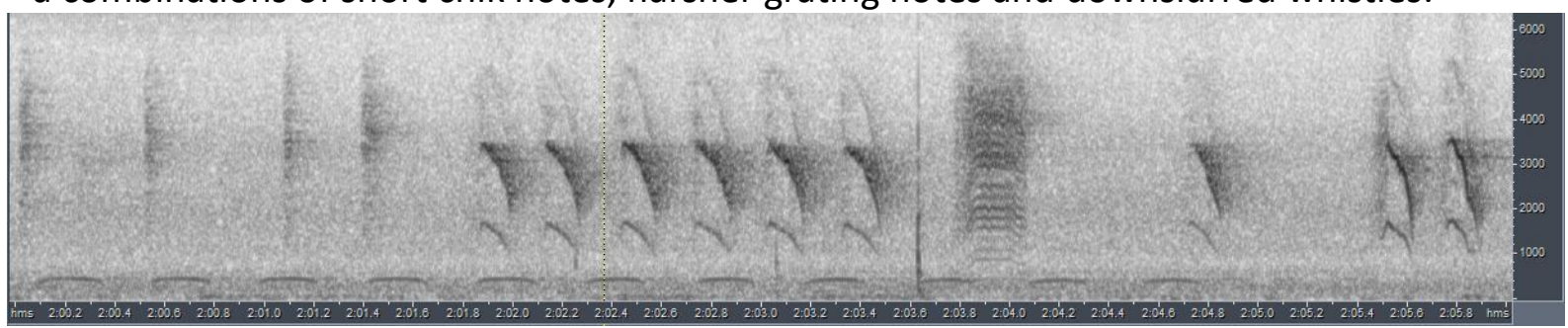

* a series of upslurred whistles with a burry start

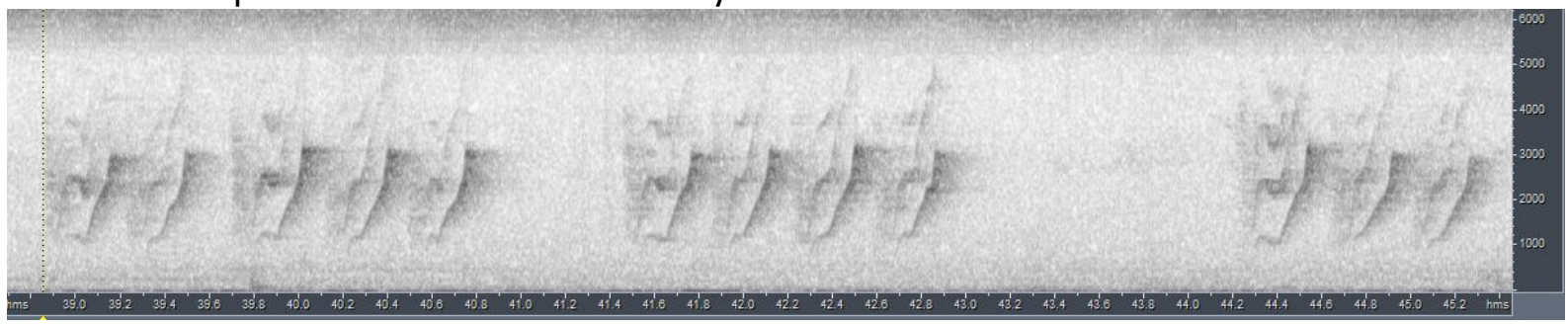

* a falling series of nasal notes

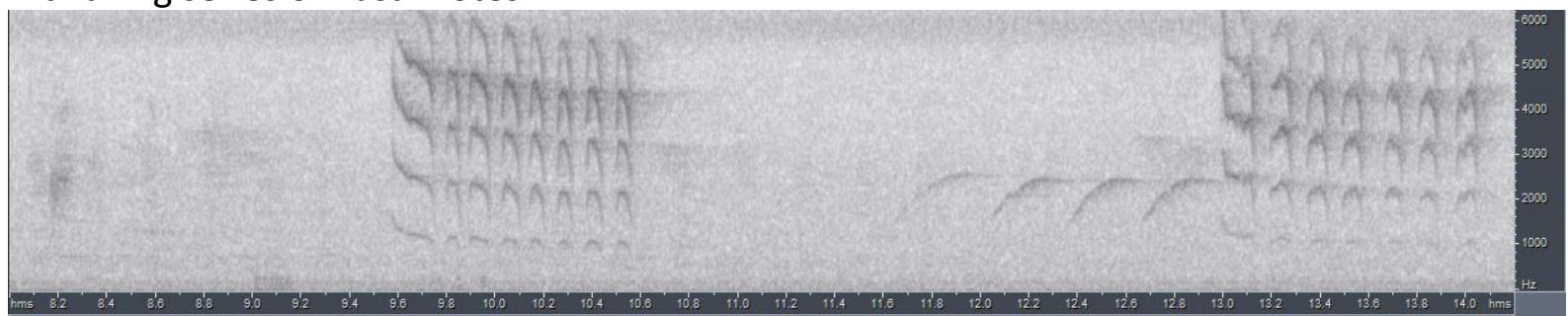

* a harsh grating note ending with a pure short sylable

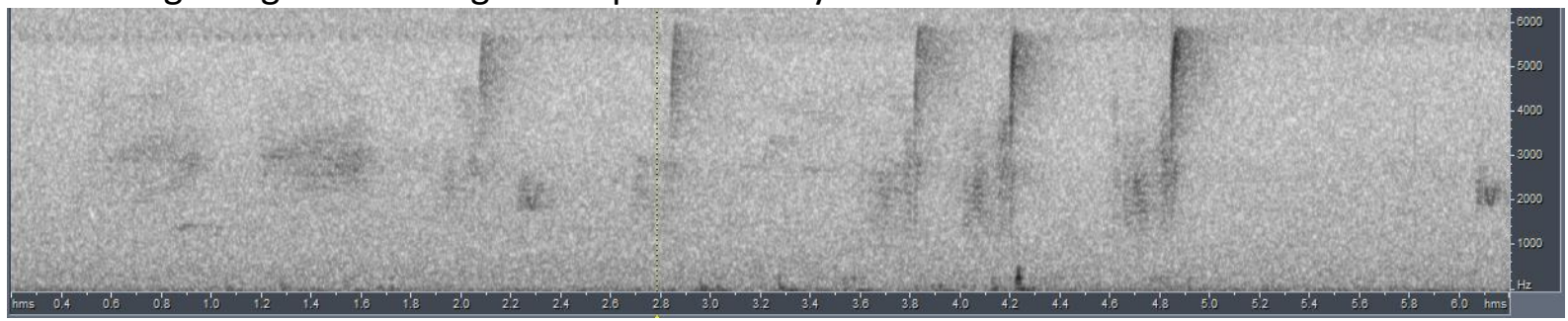

pluto (Pohnpei)

song:

* a series of upslurred whistles and grating notes

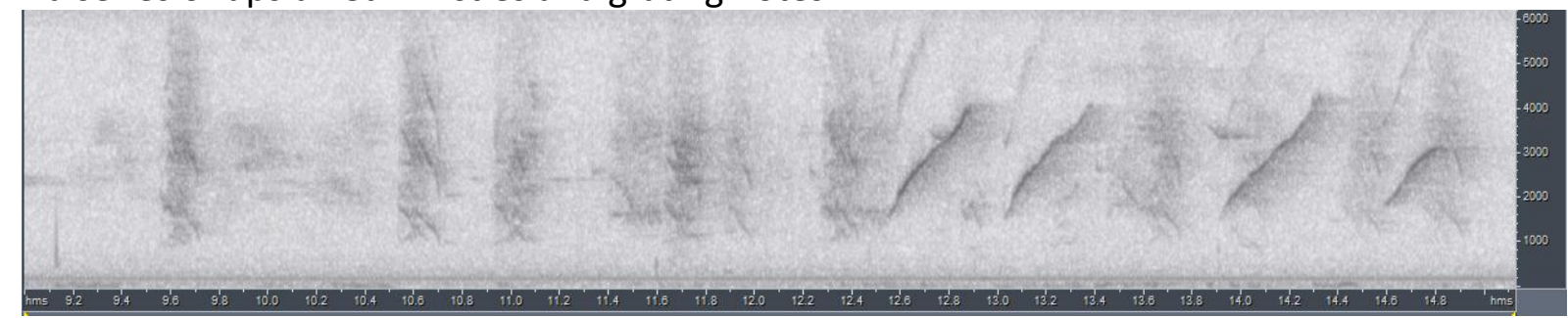




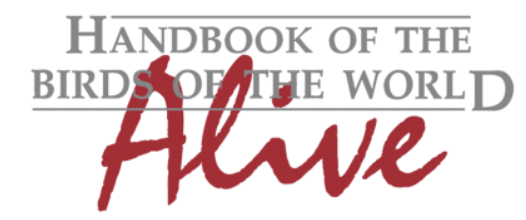

\section{ORNITHOLOGICAL NOTES}

* a faster series of whistles

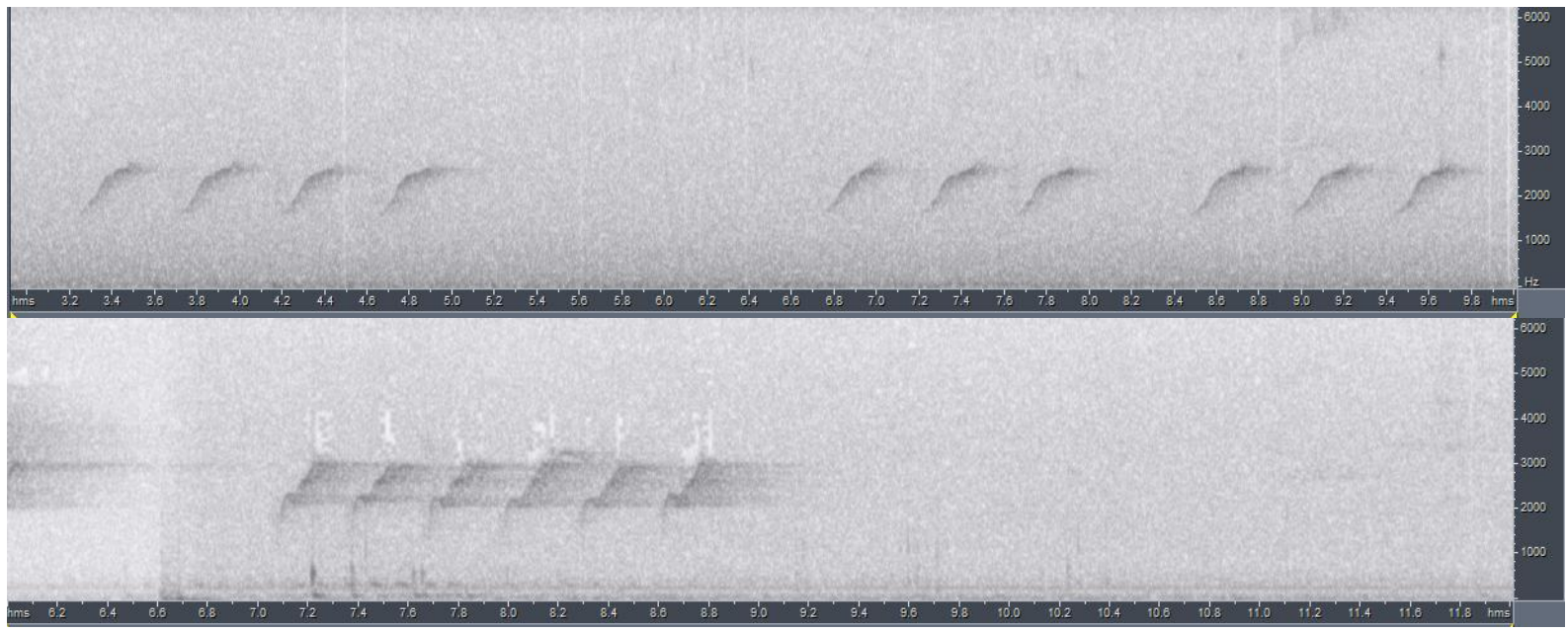

* a falling series of nasal notes

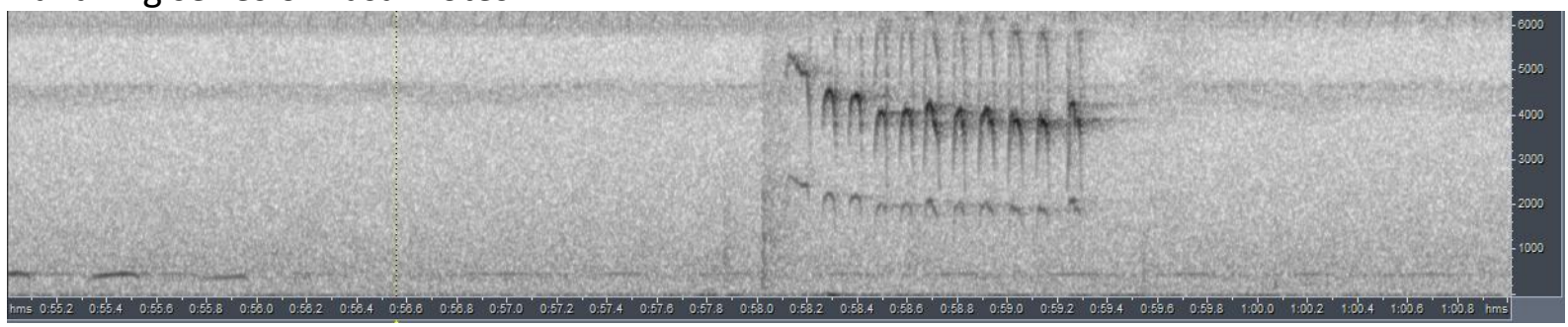

* a harsh grating note ending with a pure short sylable

From the above, it seems that erythrops is vocally the most distinctive taxon.

Out of the available recordings, only one vocalization type (harsh grating note) is shared with the other 2 races (and even then slightly different), while all song-like vocalisations are different. Differences could e.g. be quantified as the song with the smallest frequency range (c. $100-800 \mathrm{kHz}$ vs. c. $800-2000 \mathrm{kHz}$, score 3), higher-pitched fundamental frequency (min. freq. c. $3-4 \mathrm{kHz}$ vs. c. $1-2 \mathrm{kHz}$, score 3 ) and vocabulary to a large extent different (score 1-2). When applying Tobias criteria, this would lead to a total score of about 4-5.

Vocal differences between races pluto and oceanica are much less obvious, with 3 out of 4 (of the available) vocalizations similar or identical. Based on the available recordings, a score of 1 could be given for apparently a slightly different vocabulary.

This note was finalized on 18th January 2016, using sound recordings available on-line at that moment. We would like to thank in particular the sound recordists who placed their recordings for this species on XC and ML: John V Moore, Douglas Pratt and Mark Todd. 


\section{References}

Tobias, J.A., Seddon, N., Spottiswoode, C.N., Pilgrim, J.D., Fishpool, L.D.C. \& Collar, N.J. (2010). Quantitative criteria for species delimitation. Ibis 152(4): 724-746.

\section{Recommended citation}

Boesman, P. (2016). Notes on the vocalizations of Oceanic Flycatcher (Myiagra oceanica). HBW Alive Ornithological Note 192. In: Handbook of the Birds of the World Alive. Lynx Edicions, Barcelona. (retrieved from http://www.hbw.com/node/932136 on 28 August 2016). 